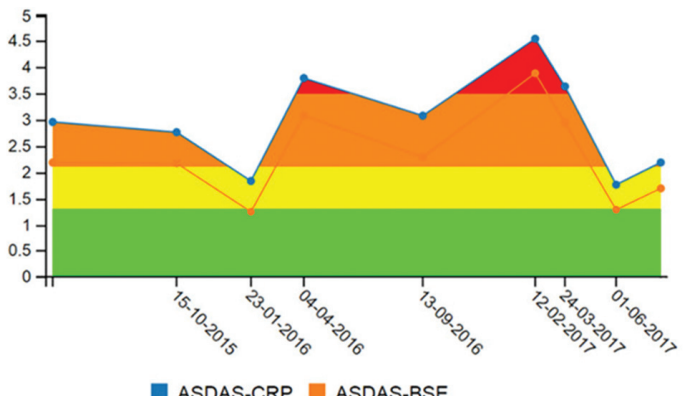

TNF-2

NSAID

TNF-1

Abstract THU0247 - Figure 1. Example of graph in SpA-Net reporting the evolution of ASDAS in relation to medication use over time

Conclusions: SpA-Net enables regular monitoring of pts with $\mathrm{SpA}$ and can serve as a first step to optimise knowledge and communication between pts and care providers. Both pts and care providers thought SpA-Net improves quality of care in daily practice.

Disclosure of Interest: C. Webers: None declared, E. Beckers: None declared, Y. van Eijk: None declared, H. Vonkeman: None declared, M. van de Laar: None declared, P. van Riel: None declared, M. Efdé: None declared, A. Boonen: None declared, A. van Tubergen Grant/research support from: AbbVie, Celgene, Janssen-Cilag, MSD, Novartis, Pfizer, UCB

DOI: 10.1136/annrheumdis-2018-eular.4763

\section{THU0248 ASSOCIATION OF KINESIOPHOBIA, AEROBIC EXERCISE, FUNCTIONAL IMPAIRMENT AND DISEASE ACTIVITY OF PATIENTS WITH RHEUMATOID ARTHRITIS AND SPONDYLOARTHRITIS}

D. peres ${ }^{1}$, N. tordi ${ }^{1}$, Y. sagawa ${ }^{2}$, D. wendling ${ }^{3}$, C. Prati ${ }^{1,3} .{ }^{1}$ Pepite ea4267, Univ. Bourgogne Franche-Comté, ${ }^{2}$ Laboratoire de l'Exploration Fonctionnelle et Clinique du Mouvement (LEFCM); ${ }^{3}$ rheumatology unit, Hopital jean minjoz, besancon cedex, France

Background: Rheumatoid arthritis (RA) and spondyloarthritis (SA) are the most common chronic inflammatory rheumatism, leading to functional disability, but also cardiovascular mortality. Aerobic exercise (AE) is one of the most effective non-pharmacological resources for cardiovascular rehabilitation while the patients RA and SA have difficulty to join the practice of physical exercise. It can be explained by the presence of kinesiophobia, fear that the movement exacerbates the pain and disease.

Objectives: To compare the level of AE of patients with RA and SA with healthy subjects and to verify the association between kinesiophobia, the level of activity of the disease and the functional disability

Methods: Fifty RA patients and fifty SA patients followed by the rheumatology department of the University Hospital of Besançon and fifty healthy age-matched subjects were included. The main inclusion criteria: between 18 and 80 years old and without orthopaedic surgery $<1$ year. The disease activity (DAS-28 and ASDAS), the functional disability (HAQ and BASFI), the level of AE (SQUASH questionnaire) and kinesiophobia (TSK questionnaire) were evaluated. The control group answered to the SQUASH questionnaire. The t-test was used to compare inflammatory rheumatism groups with the control group (healthy subjects). The Pearson Correlation Test for each group (RA and SA) was used to verify the associations between variables.

Results: The level of $A E$ is significantly higher in healthy subjects $(p=0.022)$. In the RA group, kinesiophobia is associated with disease activity, functional disability and level of $A E$. In the SA group, kinesiophobia is associated only with the functional disability. Patients have a low level of $A E$ compared to healthy subjects. However, only the RA group has an association between kinesiophobia and AE. In the SA group, functional disability appears to be a factor limiting the practice of $\mathrm{AE}$.
Abstract THU0248 - Table 1. Results of pearson correlation test between variables

\begin{tabular}{cccccc}
\hline & $\begin{array}{c}\text { Aerobic } \\
\text { Exercice }\end{array}$ & Kinesiophobie & $\begin{array}{c}\text { Functional } \\
\text { Disability }\end{array}$ & $\begin{array}{c}\text { Disease } \\
\text { Activity }\end{array}$ \\
\hline \multirow{2}{*}{ RA } & Aerobic Exercise & - & $r=-0.280^{*}$ & $r=-0.414^{* *}$ & $r=-0.149$ \\
\cline { 2 - 6 } & Kinesiophobie & $r=-0.280^{*}$ & - & $r=0.522^{* *}$ & $r=0.327^{*}$ \\
\cline { 2 - 6 } & Functional Disability & $r=-0.414^{* *}$ & $r=0.522^{* *}$ & - & $r=0.531^{*}$ \\
\hline \multirow{2}{*}{ SA } & & & & \\
\cline { 2 - 6 } & Aerobic Exercise & - & $r=-0.165$ & $r=-0.40$ & $r=-0.064$ \\
\cline { 2 - 6 } & Kinesiophobie & $r=-0.165$ & - & $r=0.345^{*}$ & $r=0.224$ \\
\cline { 2 - 4 } & $r=-0.040$ & $r=0.345^{*}$ & - & $r=0.737^{* *}$ \\
\hline${ }^{*} p<0.005 ; * p<0,005$ & & & &
\end{tabular}

Conclusions: RA and SA patients need to be encouraged and better informed about the benefits of physical exercise.

Disclosure of Interest: None declared

DOI: 10.1136/annrheumdis-2018-eular.6741

\section{THU0249 MORE THAN 60\% PATIENTS WITH SPONDYLOARTHRITIS REPORT PERIPHERAL MANIFESTATIONS: AN ANCILLARY ANALYSIS OF THE ASAS-COMOSPA STUDY}

C. López-Medina ${ }^{1,2}$, A. Moltó ${ }^{1,3}$, M. Dougados ${ }^{1,3} \cdot{ }^{1}$ Rheumatology, Cochin Hospital, Paris, France; ${ }^{2}$ Rheumatology, Hospital Universitario Reina Sofía/IMIBIC/ Universidad de Córdoba, Córdoba, Spain; ${ }^{3}$ Inserm (U1153), clinical epidemiology and biostatistics., PRES Sorbonne Paris-Cité, Paris, France

Background: Peripheral manifestations (arthritis, enthesitis and dactylitis) can be observed in patients with Spondyloarthritis $(\mathrm{SpA})^{1}$, but the factors associated with their presence are not well known. Studies are needed in order to thoroughly evaluate these symptoms.

Objectives: a) To describe the prevalence of peripheral manifestations in patients with SpA in a world-wide population; and b) to determine the factors asso ciated with the presence of these manifestations.

Methods: Data from the ASAS-COMOSPA study were analysed. The prevalence of each peripheral manifestation was evaluated with regard to the criteria fulfilled by the patient (ASAS axial, ASAS peripheral, CASPAR) and with regard to the time of occurrence of axial symptoms (before/concomitant/after). Factors associated with the presence of these peripheral manifestations were also explored by univariate and multivariate logistic regression.

Results: Out of the 3984 patients included in ASAS-COMOSPA, 2562 (64.3\%) reported, at least, one peripheral manifestation. Among these, 2051 patients (51.5\% from the total database) had current or past history of peripheral arthritis, being more frequent among patients who met CASPAR and Peripheral ASAS criteria (see figure 1). Involvement was more frequently oligoarticular $(40.2 \%)$ and appearing after axial symptom onset (48.9\%). Multivariate analysis showed that patients from South America [OR 2.45, (95\% $1.93-3.11)]$, the presence of enthesitis [OR 2.46, $(95 \% \mathrm{Cl} 2.11-2.86)$ ], dactylitis [OR 6.46, $(95 \% \mathrm{Cl} 4.78-8.71)$ ] skin psoriasis [OR 2.46, $(95 \% \mathrm{Cl} 1.79-3.37)]$, HLAB27+ [OR 0.83, (95\%Cl 0.72 $0.97)]$ and inflammatory back pain (IBP) [OR $0.37,(95 \% \mathrm{Cl} 0.29-0.47)]$ were associated with peripheral arthritis.

A total of 1506 (37.8\%) and 618 (15.6\%) patients reported enthesitis and dactylitis, respectively. Both occurred after axial symptoms onset in $58.3 \%$ and $60.8 \%$ o the patients, respectively. Similar results than peripheral arthritis were obtained in the multivariate analysis regarding these two peripheral manifestations, with exception of IBP and HLAB27+, which were not associated with enthesitis.

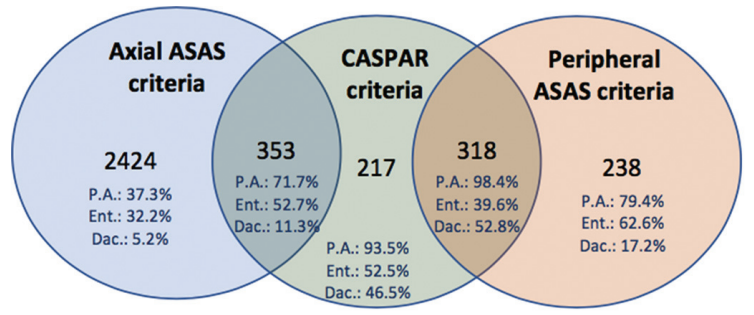

*434 patients fulfil neither axial ASAS, nor peripheral ASAS, nor CASPAR criteria. (P.A. $43.8 \%$, Ent. $34.8 \%$, Dac. $11.3 \%$ ). P.A.: Peripheral Arthritis. Ent.: Enthesitis. Dac.: Dactylitis.

Abstract THU0249 - Figure 1. *434 patients fufil neither axial ASAS, nor peripheral ASAS, nor CASPAR criteria. 
Conclusions: Peripheral manifestations appear in $64 \%$ of patients with SpA and in more than $50 \%$ after axial symptoms onset. Peripheral arthritis, were more frequently mono- or oligo- rather than poly-articular, and the presence of psoriasis or any of the three peripheral manifestations acts as risk factor for the development of other peripheral symptoms.

\section{REFERENCE:}

[1] Dougados M, d'Agostino MA, Banessiano J, et al. Joint Bone Spine 2011 Dec;78(6):589-603. doi:10.1016/j.jbspin.2011.01.013

Disclosure of Interest: None declared

DOI: 10.1136/annrheumdis-2018-eular.5309

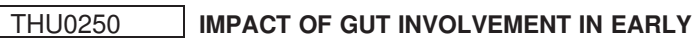 SPONDYLOARTHRITIS. THE DESIR COHORT}

D. Wendling ${ }^{1}$, X. Guillot ${ }^{1}$, C. Prati ${ }^{1}$, C. Miceli-Richard ${ }^{2}$, A. Molto ${ }^{2}$, R. Lories ${ }^{3}$, M. Dougados ${ }^{2} .{ }^{1}$ Rheumatology, CHRU Besançon, Besançon; ${ }^{2}$ Rheumatology, Cochin Hospital, Paris, France; ${ }^{3}$ Skeletal Biology, KU Leuven, Leuven, Belgium

Background: Inflammatory bowel disease (IBD) is a well-known extra articular feature of spondyloarthritis ( $\mathrm{SpA})$, with increasing evidence of a pathophysiological relationship.

Objectives: The aims of this study were to evaluate in the DESIR cohort a) the prevalence of IBD at baseline and M60, and b) the incidence of IBD over the first 5 years of follow-up, c) factors (epidemiological, clinical, imaging, biological data available in the database) associated with IBD, a on the prevalent cases at baseline and at year 5 and also on the incident cases.

Methods: DESIR is a prospective observational cohort of patients with recent onset ( $<3$ years) inflammatory back pain, suggestive of axial SpA. All available factors in the database were compared between patients with and without past or present IBD at baseline and at M60, and with and without incident cases of IBD over the 5 years of follow-up, by uni and multivariate analysis.

Results: At baseline, 706 patients were analysed, 35 had a past history or a concomitant IBD: prevalence 4.94\% [CI 95\%: 3.3-6.5]. IBD was significantly associated (univariate) with family history of IBD, DMARD use, steroid use, history of uveitis, elevated ESR and negatively associated with psoriasis, HLA-B27 and NSAID score. In multivariate analysis IBD was positively and independently associated with history of uveitis; OR 3.62 [1.95-6.74], levels of DKK-1: OR 1.03 [1.02-1.05] and TNF serum levels: OR 1.17 [1.08-1.26]. IBD was not associated with phenotypic presentation (peripheral arthritis, enthesitis, dactylitis, uveitis) or baseline serum levels of other cytokines (IL-6, IL-17 A, IL-17 F, IL-23, IL-23).

At M60, 480 patients were analysed, 58 with IBD: prevalence 12.1\% [9.17-14.99] In univariate analysis on prevalent cases, IBD was associated with lower NSAID score, worse activity and function indexes (ASDAS-CRP, BASFI, SF-36, HAQ, ASQoL), use of DMARD anti TNF, more sick leave. In multivariate analysis, IBD was associated with fulfilment of modified New York criteria: OR 4.85 [2.2310.57], sick leave: OR 1.01 [1.005-1.014], BASDAI: OR 1.10 [1.05-1.16], and with smoking: OR 2.79 [1.53-5.07]. No association with MRI scores, enthesitis, psoriasis, BMD.

After a 5 year follow-up period, 23 new incident cases of IBD were recorded, giving an estimated occurrence rate of $0.95 / 100$ [0.57-1.35] patient-years in this population. Incidence of IBD was independently associated (multivariate) with: HLA B27: OR 0.36 [0.22-0.59], fulfilment of modified New York criteria at M0: OR 3.35 [1.85-6.08], family history of IBD: OR 3.31 [1.62-6.77].

Conclusions: In early SpA, IBD occurs with an incidence of around 1/100 patient-years, and is associated with poor outcome at 5 years, family history of IBD, absence of HLA-B27, fulfilment of modified New York criteria.

Disclosure of Interest: None declared

DOI: 10.1136/annrheumdis-2018-eular.3205

\section{THU0251 CHARACTERISTICS OF NEWLY DIAGNOSED AXIAL SPONDYLOARTHRITIS PATIENTS IN RHEUMATOLOGY PRACTICES ACROSS GERMANY}

D. Poddubnyy ${ }^{1}$, E. Edelmann ${ }^{2}$, V. Rios Rodriguez ${ }^{1}$, S. Sartingen ${ }^{3}$, T. Mosch $^{3}$ J. Sieper ${ }^{1} .{ }^{1}$ Charité Universitätsmedizin Berlin, Berlin; ${ }^{2}$ Rheumazentrum Bad Aibling, Bad Aibling; ${ }^{3}$ AbbVie Deutschland GmbH and Co KG. Wiesbaden, Germany

Background: There is still limited knowledge about early axial spondyloarthritis (axSpA) patients in primary rheumatology care.

Methods: Rheumatologist from $n=70$ study centres across Germany recruited patients with spondyloarthritis $(\mathrm{SpA})$ diagnosed for the first time (time since diagnosis $<1$ year) over three consecutive years. Patients were evaluated and documented regarding clinical, laboratory and imaging characteristics, fulfilment of ASAS classification criteria and treatment. In addition, participating centres $(n=36)$ documented the frequency of newly diagnosed SpA among all patients seen for the first time in their practice in one week.

Results: A total of 427 newly diagnosed SpA patients were recruited. 342 patients (mean age 38.9 years, range $18-73 ; 55.3 \%$ males) had a new diagnosis of axSpA (mean symptom duration 81.5 months (range 0-599)) and are presented here in more detail. $36.5 \%$ were classified as radiographic axSpA according to the modified New York criteria and $19.3 \%$ were imaging (magnetic resonance imaging and X-rays) negative. The laboratory, clinical and imaging characteristics of these patients are shown in the table $1.85 .4 \%$ of these patients diagnosed as axSpA by the rheumatologist fulfilled the ASAS classification criteria. $69.9 \%$ were treated with NSAIDs, $3.8 \%$ with conventional DMARDs and $1.2 \%$ with biologics when seen for the first time by the rheumatologist. The therapy has been continued or changed as follows by the rheumatologist at first visit after making the diagnosis of axSpA: NSAIDs in $80.7 \%$, conventional DMARDs in $8.8 \%$ and biologics in $10.5 \%$. However, additional treatment with biologics might be initiated at follow-up visits.

The proportion of SpA patients among all newly diagnosed patients with rheumatic conditions documented in one week was $17.5 \%(10.1 \%$ axSpA and $7.4 \%$ peripheral SpA)

Abstract THU0251 - Table 1. Clinical, laboratory and clinical characteristics of patients with axial SpA $(\mathrm{n}=342)$

\begin{tabular}{lc}
\hline Parameter & Prevalence, $\%$ \\
\hline Inflammatory back pain, current & 74.9 \\
Arthritis, current & 14.6 \\
Enthesitis, current & 10.5 \\
Positive family history & 18.1 \\
Uveitis, ever & 12.0 \\
Psoraisis, ever & 10.5 \\
Inflammatory bowel disease, current & 1.8 \\
HLA-B27 positiv & 69.6 \\
CRP positive, current & 37.7 \\
MRI sacroiliac joints positive, current & 60.8 \\
MRI spine positive, current & 11.7 \\
Definite radiographic sacroiliitis (X-ray positive) & 29.5 \\
MRI and X-ray negative & 19.3 \\
\hline
\end{tabular}

Conclusions: The characteristics of axSpA patients seen in primary rheumatology practices are comparable to what has been reported. The majority of patients are still in the stage of non-radiographic axSpA when diagnosed first and the majority of patients have active MRI inflammation in the sacroiliac joints but not in the spine. In about $10 \%$ of patients a TNF-blocker was started already at first visit. Disclosure of Interest: D. Poddubnyy Grant/research support from: AbbVie MSD, Novartis., Consultant for: AbbVie, BMS, Boehringer, MSD, Novartis, Pfizer, and UCB., Speakers bureau: AbbVie, BMS, Janssen, MSD, Novartis, Pfizer, and UCB., E. Edelmann Consultant for: AbbVie, Boehringer-Ingelheim, Lilly, Mundipharma, MSD, Novartis, Pfizer, Roche, UCB., V. Rios Rodriguez Consultant for: Abbvie, MSD and Novartis., S. Sartingen Shareholder of: AbbVie Inc., Employee of: AbbVie Deutschland GmbH and Co. KG., T. Mosch Shareholder of: AbbVie Inc., Employee of: AbbVie Deutschland GmbH and Co. KG., J. Sieper Grant/ research support from: AbbVie, Merck, and Pfizer., Consultant for: AbbVie, Janssen, Lilly, Merck, Novartis, Pfizer, and UCB., Speakers bureau: AbbVie, Janssen, Merck, Novartis, Pfizer, Roche, and UCB.

DOI: 10.1136/annrheumdis-2018-eular.1917

\section{THU0252 THE RATE OF US VERIFIED HIP INVOLVEMENT IN PATIENTS WITH ANKYLOSING SPONDYLITIS}

E. Agafonova ${ }^{1}$, T. Dubinina ${ }^{2}$, A. Dyomina ${ }^{2}$, O. Rumyantseva ${ }^{1}$, S. Erdes ${ }^{1}$. ${ }^{1}$ Laboratory Spondyloarthritis; ${ }^{2}$ Laboratory of Scientific Organizational Problems in Rheumatology, V.A. Nasonova Research Institute of Rheumatology, Moscow, Russian Federation

Background: Hip joint $(\mathrm{HJ})$ involvement is one of the most common extra-axial manifestations of ankylosing spondylitis (AS).

Objectives: To correlate clinical manifestations of coxitis with the ultra-sound findings in AS patients.

Methods: 224 consecutive AS patients (mean age 33,2 $\pm 14,2$ y) meeting 1984 modified N-Y criteria and hospitalised in V.A. Nasonova Research Institute of Rheumatology with hip pain were evaluated. Patients' mean age at the onset of the disease was $26,3 \pm 20,3$ y., 93\% of them were HLA-B27-positive. Median AS duration was 57 [12-444] months, the BASDAI score was $5,7 \pm 3,1$. The diagnosis of coxitis was based on clinical signs and symptoms, such as inguinal pain and/o limitation in the range of hip motion (ROM) at the time of patients' admission to the clinic. All patients (regardless current complaints) were subjected to ultrasound 